\title{
The stress analysis in electric poles with CFRP to prevent the consecutive demolishing from car accidents
}

\author{
Suchat Suvimolwan ${ }^{1}$ and Atavit Sujaritpong ${ }^{1}$ \\ ${ }^{1}$ Civil Engineering Department, Faculty of Engineering, King Mongkut's Institute of Technology Ladkrabang, Bangkok, Thailand
}

\begin{abstract}
In statistically accidental reports, we could find progressive collapse of prestressed concrete electric poles from car accident, this is due to the poor properties of concrete which limits the impact resistance, the failure will therefore occur in the position of impact where maximum stress is presented near the base. The weight of broken concrete at above the failure position will cause the impact force to the adjacent electric poles, resulting in consecutive damage and increase the tensile force in electric cables. This research will emphasize repositioning of failure at pole base by application of CFRP material. Finite element analysis will be introduced to analyse the thickness of CFRP in order to control the desired point of failure. The result can be a guideline to prevent the consecutive demolishing for the existing electric poles later on.
\end{abstract}

\section{Introduction}

Generally, the manufacturing of electric pole according to the Metropolitan Electricity Authority's standard by concrete has been using as the main material for long, this is because concrete can be casted to shapes and sizes as desired including when considering cost and strength properties. However, due to the limitation of concrete itself especially flexural strength and brittle property of concrete are weak, we therefore can see many cases of consecutive broken down which occurred by the accidental from car crash.

Based on the incidents, this showed the strength of concrete is still not strong enough for the damage of electric poles. The consecutive broken down of electric poles mostly occurred at the position near by the pole base which highest moment was achieved. The tension force by weight of broken poles from the car crash was transferred thru the cable and to the next the poles at the top part, this caused the progressive broken to numbers of poles.

\section{The failure of concrete poles, CFRP and related materials}

\subsection{The failure of concrete poles}

The failure of concrete pole will occur in the position of impact where maximum stress is presented near the base. The concrete weight above the failure position will cause the impact force to the adjacent electric poles, resulting in consecutive damage and increase the tensile force in electric cables. To minimize the weight beyond the failure position is therefore considered to decrease these impact forces to the adjacent poles and may present the consecutive damage consequently.

\subsection{Resulting of bending moment from the tensile force thru the cable}

The resistance to the bending moment of concrete pole which installed cables and various accessories can be explained in Eq.1.

$$
\text { B.M. }=\mathrm{F} \times \mathrm{S}
$$

Where B.M. is bending moment, $\mathrm{F}$ is tensile force and $\mathrm{S}$ is the distance of tensile force to the ground base.

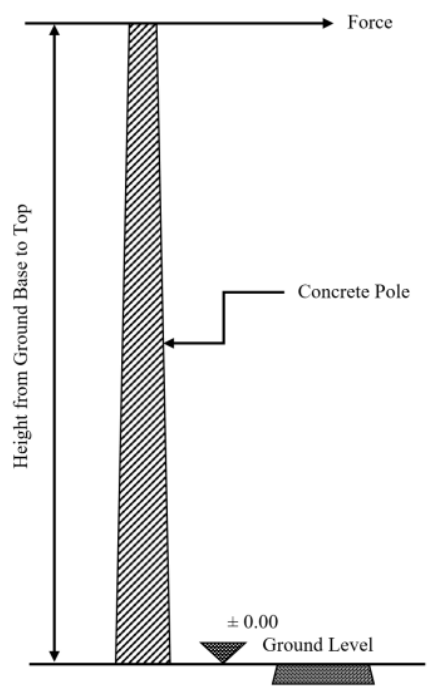

Fig. 1. Position of force from the cable

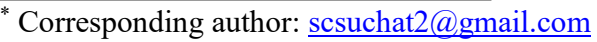




\subsection{Pre-stressed electric concrete poles}

Based on the Metropolitan Electricity Authority's standard concrete electric poles has been manufactured in different heights with desired strength and bending moment for various functions. Table 1 is shown 4 main materials of concrete poles with the details of tensile strength as following.

Table 1. Strength of materials in concrete poles

\begin{tabular}{|c|c|c|}
\hline Materials & $\begin{array}{c}\text { Strength of } \\
\text { Materials }\end{array}$ & Units \\
\hline Concrete & 450 & $\mathrm{kgf} / \mathrm{cm}^{2}$ \\
\hline Pre-stressed Wires & 12,500 & $\mathrm{kgf} / \mathrm{cm}^{2}$ \\
\hline Stirrup Steel & 2,400 & $\mathrm{kgf} / \mathrm{cm}^{2}$ \\
\hline CFRP Fabric & 35,500 & $\mathrm{kgf} / \mathrm{cm}^{2}$ \\
\hline
\end{tabular}

In this study, the concrete poles height of $12 \mathrm{~m}$. with the bending moment of $3.5 \mathrm{~T}-\mathrm{m}$., $12 \mathrm{~m}$. with bending moment of $5 \mathrm{~T}-\mathrm{m}$. and $12.35 \mathrm{~m}$. with bending moment of $6.5 \mathrm{~T}-\mathrm{m}$. will be used as the models in Finite Element Analysis, these 3 models will be called $12 \mathrm{GW}, 12 \mathrm{~m}$ and $12.35 \mathrm{~m}$ respectively in this study.

\subsection{CFRP materials and properties}

The prevention of consecutive damage in electric poles can be achieved by the strengthening with the application of Carbon Fibre Reinforced Plastic (CFRP), unidirectional fibre fabric type is considered to use due to the reason of high strength of CFRP material, easily to wrap the shapes of concrete poles and the cost is also reasonable when compared to other types.

Table 2. Strength of Materials

\begin{tabular}{|c|c|c|c|c|}
\hline Properties & $\begin{array}{c}\text { CFRP } \\
\mathbf{2 0 0 g} / \mathbf{m}^{\mathbf{2}}\end{array}$ & $\begin{array}{c}\text { CFRP } \\
\mathbf{2 3 0 g} / \mathbf{m}^{\mathbf{2}}\end{array}$ & $\begin{array}{c}\text { CFRP } \\
\mathbf{3 0 0 g} / \mathbf{m}^{2}\end{array}$ & $\begin{array}{c}\mathbf{C F R P} \\
\mathbf{5 3 0 g} / \mathbf{m}^{2}\end{array}$ \\
\hline $\begin{array}{c}\text { Design } \\
\text { Thickness }\end{array}$ & 0.11 & 0.13 & 0.17 & 0.29 \\
\hline $\begin{array}{c}\text { Ultimate } \\
\text { Elongation }\end{array}$ & \multicolumn{3}{|c|}{$2.10 \%$} \\
\hline $\begin{array}{c}\text { Tensile } \\
\text { strength }\end{array}$ & $\begin{array}{c}35,500 \mathrm{kgf} / \mathrm{cm}^{2} \\
\text { "Design Value" }\end{array}$ \\
\hline $\begin{array}{c}\text { Tensile E- } \\
\text { Modulus }\end{array}$ & \multicolumn{3}{|c}{$\begin{array}{c}\text { 2.35x10 } \\
\text { "Dgf } / \mathrm{cm}^{2}\end{array}$} \\
\hline
\end{tabular}

Wrapping the concrete poles with CFRP is to strengthen and to increase the ductility of the concrete poles where the maximum stress is expected. The height of wrapping will be desired as the position of cracking control for the selected concrete poles. Thickness of $0.13 \mathrm{~mm}, 0.17 \mathrm{~mm}$, $0.26 \mathrm{~mm}$ and $0.34 \mathrm{~mm}$ by CFRP will be applied in each 3 models for FEM analysis, this is for the total of 12 models plus 3 reference models without CFRP wrapping. The properties and details of CFRP Materials are given in Table 2.

\subsection{Concrete footing at the ground base}

The analysis will also consider the practical of CFRP installation with the existing concrete poles, as a result the concrete footing will be applied and casted after CFRP wrapping, the desired position is at the ground level which is $30 \mathrm{~cm}$. deep down and upward from this ground base. The thickness of concrete footing will be 2 times of the section areas of pole at the base, this is also to avoid the stress occurred under the ground base and to be practical for on-site installation of CFRP.

\section{Modelling and Analysis by FEM}

In this paper the finite element analysis will be introduced to analyse which materials will take the maximum stress as well the safety factor ratio of compressive strength in concrete on the compression zone, including the analysis on the thickness of CFRP wrapping in order to control the desired position of failure.

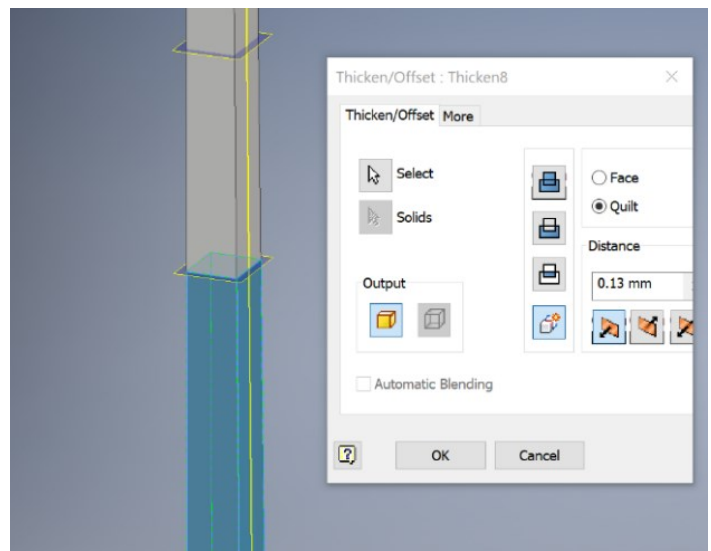

Fig. 2. Thickness of CFRP in FEM program

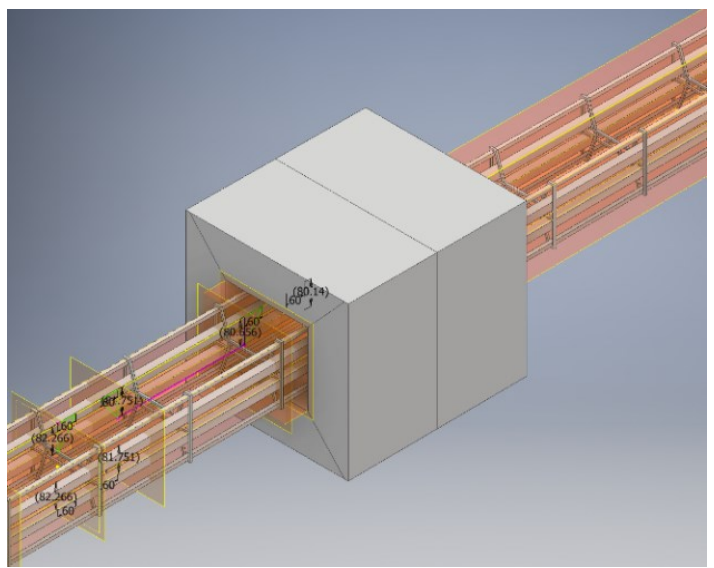

Fig. 3. Concrete Footing in the model

15 models will be created in Inventor program including reference models without CFRP, the solid body of models will consist of Concrete, Pre-stressed Wires, Stirrup Steel, CFRP Fabric and Concrete Footing at the ground level which require different menu in Inventor program, the thickness of CFRP were built in 4 types in between of $0.13 \mathrm{~mm}$ until $2.8 \mathrm{~mm}$ related to the result analysis required on each models as shown in Fig. 2 and 3. 
Table 3 is shown the details of concrete poles, uniform loads, wrapping position, tensile forces and base level used with models in FEM analysis.

Table 3. Loads and tensile forces to use in FEM Analysis

\begin{tabular}{|c|c|c|c|c|}
\hline $\begin{array}{c}\text { Concrete } \\
\text { Poles }\end{array}$ & $\begin{array}{c}\text { Uniform } \\
\text { Load } 1 \\
\text { and } 2 \\
\text { (Mpa) }\end{array}$ & $\begin{array}{c}\text { CFRP } \\
\text { Wrap } \\
\text { ping } \\
(\mathrm{m} .)\end{array}$ & $\begin{array}{c}\text { Force } \\
\text { (Wrap \& } \\
\text { Upwrapped } \\
\text { ) x Factor } \\
2.0(\mathbf{N}) \\
\end{array}$ & $\begin{array}{c}\text { Base } \\
\text { Level } \\
\text { (m.) }\end{array}$ \\
\hline \multirow{2}{*}{$\begin{array}{c}12 \mathrm{GW} \\
(3.5 \mathrm{~T}-\mathrm{m})\end{array}$} & 5.87 & \multirow{2}{*}{6.05} & $11,541.18$ & \multirow{4}{*}{1.75} \\
\hline & 14.12 & & $6,699.51$ & \\
\hline \multirow{2}{*}{$\begin{array}{c}12 \mathrm{~m} .(5 \mathrm{~T}- \\
\mathrm{m})\end{array}$} & 7.34 & \multirow{2}{*}{6.00} & $16,350.00$ & \\
\hline & 17.64 & & $9,570.73$ & \\
\hline \multirow{2}{*}{$\begin{array}{c}12.35 \mathrm{~m} \\
(6.5 \mathrm{~T}-\mathrm{m})\end{array}$} & 9.27 & \multirow{2}{*}{5.30} & $18,089.36$ & \multirow{2}{*}{2.10} \\
\hline & 23.45 & & $12,441.95$ & \\
\hline
\end{tabular}

The installation of CFRP are based on the standard procedure recommended by manufacturer with the special adhesives in reality, direction of fibre will be parallel to the height of poles in order to take on the action of tensile force transferred thru the cables from the broken poles.

\section{Analysis results}

The analysis was run by ANSYS program for all poles models, the deformation results of unwrapped are 27, 30, $20 \mathrm{~cm}$ for $12 \mathrm{GW}, 12 \mathrm{~m}$ and $12.35 \mathrm{~m}$ respectively. Fig.4 is shown the contour of deformation of the FEM analysis.

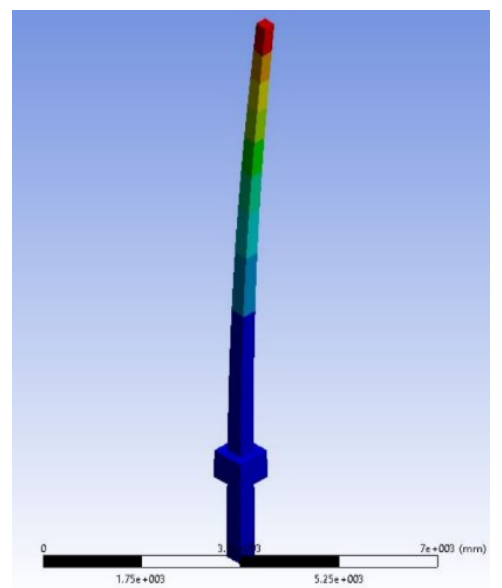

Fig. 4. Deformation contour from FEM Analysis of Models

The analysis result by FEM program on the wrapped model of $12 \mathrm{~m}$. $(3.5 \mathrm{~T}-\mathrm{m})$ gave the deformation value of 42 , 41,40 and $39 \mathrm{~cm}$ which was slightly decreased when thickness was increasing but higher than unwrapped. While the maximum stress are 699, 675, 653 and $647 \mathrm{MPa}$ and mainly occurred in CFRP materials, these stress were just $19 \%$ of CFRP's tensile strength, resulting by the thickness of $0.34 \mathrm{~mm}, 0.51 \mathrm{~mm}, 1.2 \mathrm{~mm}$ and $1.4 \mathrm{~mm}$ respectively. The details are shown in Fig. 5.

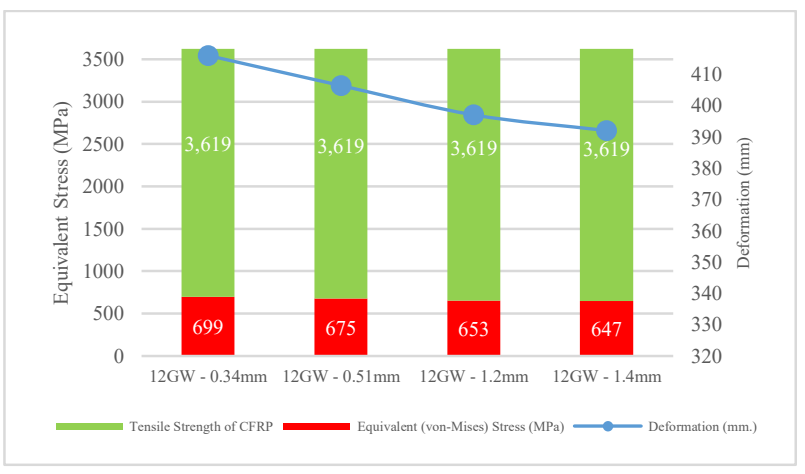

Fig. 5. Stress and Deformation Analysis of 12m. (BM 3.5T-m)

Considering the ratio of safety factor in compression zone, this analysis showed the potential of failure position on the height of poles, the result showed that increasing thickness of CFRP on the models could shift up the safety factor value at the poles base to be 1.05 while values at the position beyond the wrapping were shifted down below 1 . This result showed that the thickness at $1.4 \mathrm{~mm}$ is the most effective and safety for both deformation and prevention failure at the pole base. Fig. 6 is shown the relationship of safety factor ratio and the height of models.

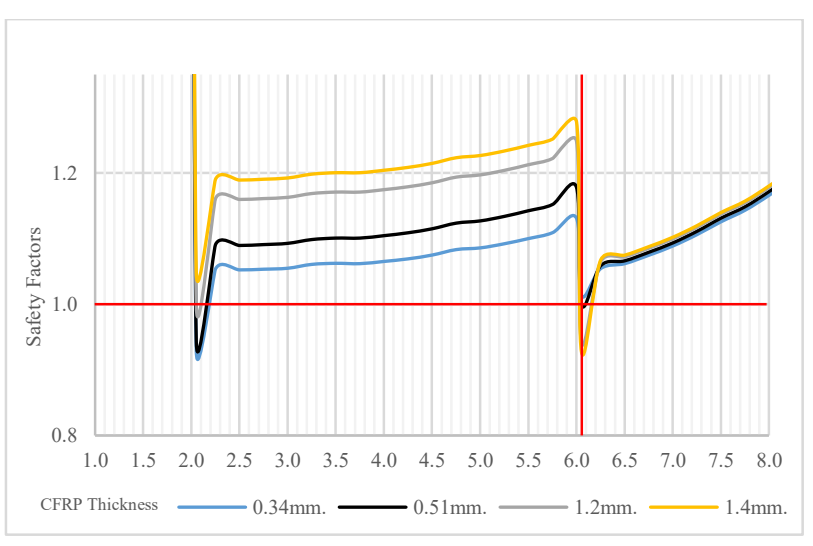

Fig. 6. Graph of Safety Factor Analysis of $12 \mathrm{~m}$. (3.5T-m)

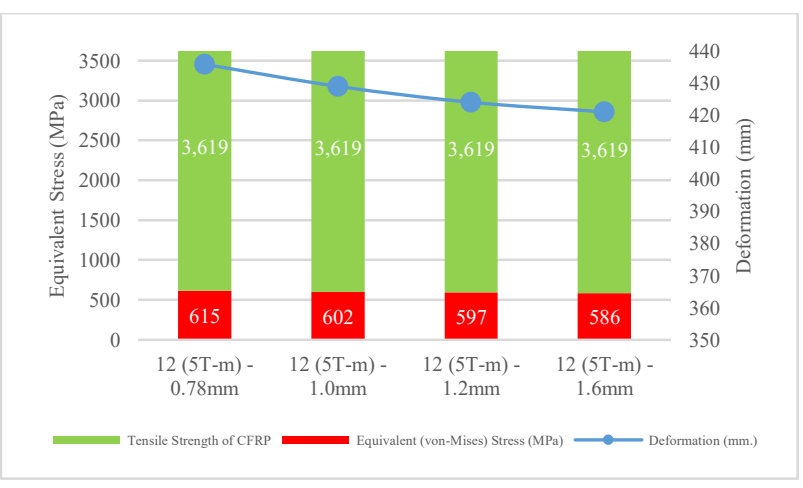

Fig. 7. Stress and Deformation Analysis of 12m. (5 T-m)

The analysis result of $12 \mathrm{~m}$. (5T-m) by FEM program is shown is Fig.7. The result gave the deformation value of $44,43,42$ and $42 \mathrm{~cm}$ which were not much different when 
thickness was increasing. While the maximum stress showed some decrease from $615,602,597$ to $586 \mathrm{MPa}$ and mainly occurred in CFRP materials, these stress were just $17 \%$ of CFRP's tensile strength, resulting by the thickness of $0.78 \mathrm{~mm}, 1.0 \mathrm{~mm}, 1.2 \mathrm{~mm}$ and $1.6 \mathrm{~mm}$ respectively.

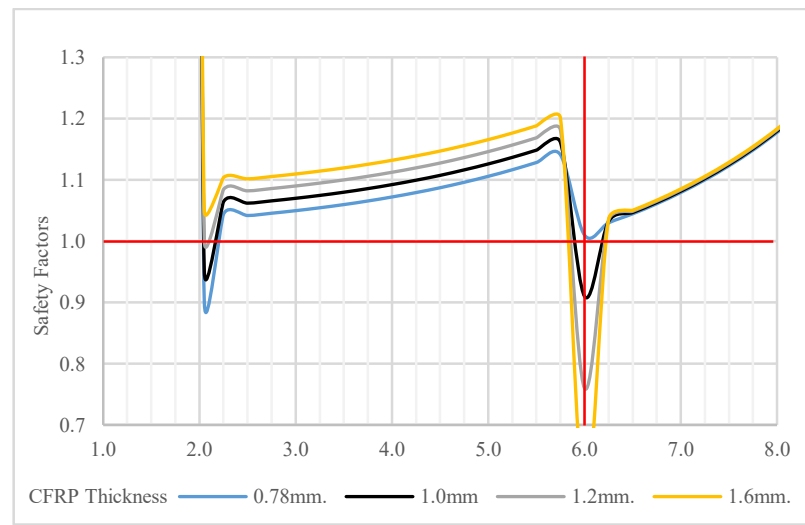

Fig. 8. Safety Factor Analysis of 12m. (BM 5T-m)

The analysis of safety factor in compression zone on $12 \mathrm{~m}$. (BM 5T-m) were started with CFRP at $0.78 \mathrm{~mm}$ thickness which result showed the failure at the ground level, increasing thickness to $1.0 \mathrm{~mm}, 1.2 \mathrm{~mm}$ and $1.6 \mathrm{~mm}$ were introduced with the pole models, and finally at $1.6 \mathrm{~mm}$ could give the best result which shifted up the safety factor higher than 1 while the values at $6 \mathrm{~m}$ were shifted down below 1. Fig. 8 is shown the safety factor ratio based on the height of models.

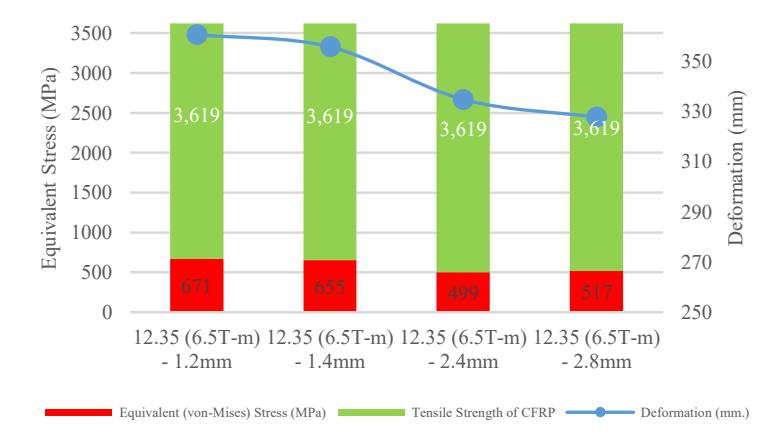

Fig. 9. Stress and Deformation Analysis of $12.35 \mathrm{~m}$.

The analysis result by FEM on model of $12.35 \mathrm{~m}$. (6.5T$\mathrm{m})$ gave the deformation value at $36,36,34$ and $33 \mathrm{~cm}$ for the different of CFRP thickness. While the maximum stress are 671, 655, 499 and $517 \mathrm{MPa}$ and mainly occurred in CFRP, these stress were just $18.5 \%$ of CFRP's tensile strength resulting by the thickness of $1.2 \mathrm{~mm}, 1.4 \mathrm{~mm}$, $2.4 \mathrm{~mm}$ and $2.8 \mathrm{~mm}$ respectively as shown in Fig. 9. While the post-cracking by safety factor analysis of $12.35 \mathrm{~m}$ pole model, the FEM analysis gave the similar result to the others. CFRP at $1.2 \mathrm{~mm}$ thickness was introduced as the $1^{\text {st }}$ model for the analysis, the result showed the failure at the ground base, therefore 3 more thickness of $1.4 \mathrm{~mm}, 2.4 \mathrm{~mm}$ and $2.8 \mathrm{~mm}$ were built. CFRP at $2.4 \mathrm{~mm}$ could give the safety factor higher than 1 at ground base while it shifted down the value below 1 at the position above the wrapping of CFRP. Fig. 10 is shown the relationship of safety factor and height of pole model.

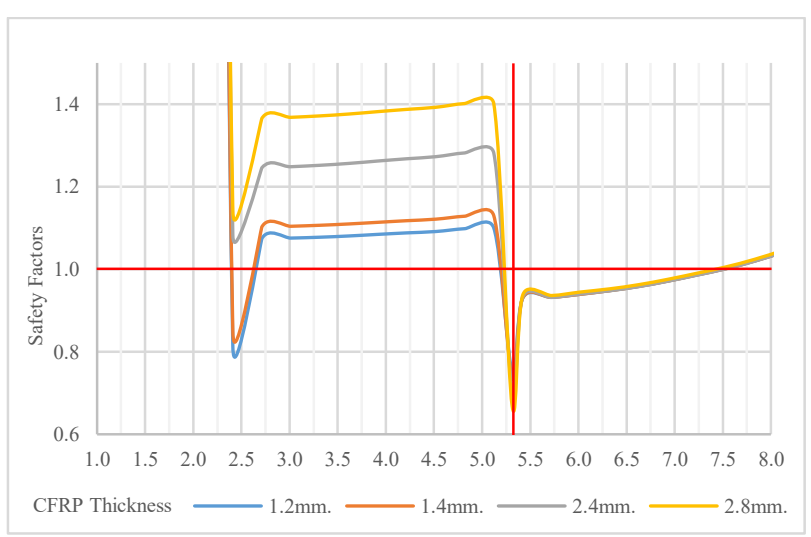

Fig. 10. Safety Factor Analysis of 12.35m. (BM 6.5 T-m)

\section{Conclusion}

The analysis result by FEM program from the application of CFRP material showed the prevention of failure at the poles base with the effective thickness of $1.4 \mathrm{~mm}$., $1.6 \mathrm{~mm}$. and $2.4 \mathrm{~mm}$, and the result of the maximum stress occurred at CFRP materials instead of rebar or concrete while the maximum stress values are at $19 \%, 17 \%$ and $18.5 \%$ for the models of $12 \mathrm{GW}, 12 \mathrm{~m}$. and $12.35 \mathrm{~m}$. respectively, these are still within the tensile strength of CFRP material. Considering the position of post-cracking in concrete poles which were analysed by the ratio of safety factor at the compression zones, the result of wrapped poles with CFRP could give the higher values than 1 at the ground base, while the results at above wrapping position was below 1 , this could prove that the stress to break down the poles, moved up beyond the position of wrapping areas as per the desired position.

Therefore this study showed the improvement successfully to strengthen and prevent the consecutive demolishing for the electric concrete poles by CFRP material which were analysed by FEM.

\section{Acknowledgement}

This study was supported by Dr. Atavit Sujaritpong and Dr. Artit Petchsasithorn from the Faculty of Engineering at King Mongkut's Institute of Technology Ladkrabang for all the advices.

\section{References}

1. Metropolitan Electricity Authority, Products and Transportation Department, 2017, The Instruction of Standard Drawing of Electric Prestressed Concrete Poles 12m (GW), 12m (BM 3.5T-m.), 12.35m (BM 6.5T-m)

2. Ministry of Interior, Department of Public Works and Urban Planning, 2008, "MorYorPhor.1508-51 The Standard of Structure Strengthening Reinforced Concrete Structures with Composite Fibre Materials", Bangkok 